\title{
Self-passivating smart tungsten alloys for DEMO: a progress in joining and upscale for a first wall mockup
}

\author{
Diana Bachurina ${ }^{1}$ Xiao-Yue Tan ${ }^{2,3} \cdot$ Felix Klein $^{3} \cdot$ Alexey Suchkov $^{1} \cdot$ Andrey Litnovsky $^{1,3}$ - Janina Schmitz ${ }^{3}$. \\ Jesus Gonzalez-Julian ${ }^{3} \cdot$ Martin Bram $^{3} \cdot$ Jan Willem Coenen ${ }^{3,4} \cdot$ Yu-Cheng Wu $^{2,5} \cdot$ Christian Linsmeier $^{3}$
}

Received: 11 November 2020 / Revised: 27 January 2021 / Accepted: 29 January 2021 / Published online: 13 April 2021

(c) The Author(s) 2021

\begin{abstract}
Self-passivating, so-called smart alloys are under development for a future fusion power plant. These alloys containing tungsten, chromium and yttrium must possess an acceptable plasma performance during a regular plasma operation of a power plant and demonstrate the suppression of non-desirable oxidation of tungsten in case of an accident. The up-scaling of the bulk smart alloys to the reactor-relevant sizes has begun and the first samples with a diameter of $50 \mathrm{~mm}$ and thickness of $5 \mathrm{~mm}$ became available. The samples feature high relative density of above $99 \%$ and good homogeneity. With production of bulk samples, the research program on joining the smart alloy to the structural material was initiated. In a present study, the novel titanium-zirconium-beryllium braze was applied successfully to join the smart alloy to the Rusfer-reduced-activation steel. The braze has survived at least a hundred of cyclic thermal excursions in the range of $300-600{ }^{\circ} \mathrm{C}$ without mechanical destruction.
\end{abstract}

Keywords Fusion power plant $\cdot$ Self-passivating smart tungsten alloys $\cdot$ Joining $\cdot$ Up-scaling production $\cdot$ Field-assisted sintering technology

\section{Introduction and motivation}

The design of the future fusion power plant is presently under intensive study worldwide. A fusion power plant needs to comply with the highest operational and safety standards [1]. Specifically, safety requirements will have a

Diana Bachurina

dmbachurina@mephi.ru

Xiao-Yue Tan

xytan@hfut.edu.cn

$\triangle$ Andrey Litnovsky

a.litnovsky@fzjuelich.de

1 National Nuclear Research University MEPhI, 115409 Moscow, Russia

2 School of Materials Science and Engineering, Hefei University of Technology, Hefei 230009, China

3 Institute für Energie und Klimaforschung, Forschungszentrum Jülich GmbH, 52425 Jülich, Germany

4 Department of Engineering Physics, University of Wisconsin-Madison, Madison, WI 53706, USA

5 Key Laboratory of Interface Science and Engineering of New Materials, Ministry of Education, Taiyuan University of Technology, Taiyuan 030024, China strong effect on the design and on the choice of components and materials. Plasma-facing materials (PFMs) are crucially important for a robust plasma operation of the power plant. Due to advantages such as a high threshold energy for sputtering, low tritium retention, high thermal conductivity, high melting point and moderate activation, tungsten (W) is presently chosen as a prime candidate PFM for the European DEMOnstration fusion power plant, DEMO [2].

However, the predictive modeling [3] performed for various accidental scenarios on DEMO has revealed a decisive drawback of pure tungsten. In case of the so-called loss-ofcoolant accident (LOCA) with an air ingress the temperature of the tungsten cladding reaches $1000{ }^{\circ} \mathrm{C}$ and remains at such a high level for several weeks. At such a high temperature, tungsten oxidizes and radioactive neutron-activated tungsten oxide sublimates into the atmosphere. Recent studies predict the sublimation rates from 10 up to $150 \mathrm{~kg}$ per hour from the first wall of a future fusion power plant [4].

Self-passivating tungsten alloys were introduced as a concept by Koch and Bolt [5]. During regular plasma operation, the surface of tungsten alloys is bombarded by plasma particles. Plasma bombardment leads to preferential sputtering of the light alloying elements leaving an almost pure tungsten surface facing the plasma. In a 
case of an accident, the remaining alloying elements in the bulk of the alloy will react with air and create their own dense oxides protecting tungsten from oxidation and from subsequent sublimation. Modern, self-passivating, the so-called smart alloys (SA) [6, 7], contain chromium $(\mathrm{Cr})$ as oxidizing alloying element and yttrium $(\mathrm{Y})$ as an active element stabilizing and regulating the chromium transport in the alloy system. The most efficient alloy composition was found to be $88 \mathrm{wt} . \%$ of W, $11.4 \mathrm{wt} . \%$ of $\mathrm{Cr}$ and 0.6 wt.\% of $\mathrm{Y}[4]$.

Sound progress was made in development of smart alloys recently: bulk smart alloy samples became available via mechanical alloying (MA) followed by a fast compacting using field-assisted sintering technology (FAST), also known as spark plasma sintering (SPS) [8]. The availability of bulk SA samples allowed performing the extensive qualification of smart alloys. The essential elements of this qualification are an acceptable plasma performance of smart alloys and a suppression of oxidation of the new alloy systems. The bulk $\mathrm{W}-\mathrm{Cr}-\mathrm{Y}$ systems have demonstrated an impressive resistance to sputtering by deuterium plasmas on the timescale of three weeks of continuous DEMO operation [9]. At the same time, bulk smart alloy samples have attained an outstanding resistance to oxidation. The oxidation rate of smart alloys is at least a factor of $10^{5}$ lower than that of pure tungsten. The resulting sublimation was also exceptionally reduced: at least a 40 -fold decrease of sublimation was observed on $\mathrm{W}-\mathrm{Cr}-\mathrm{Y}$ smart alloy as compared with that of pure tungsten [10].

This qualification of smart alloys is a further step towards realization of the prototype first wall component of the fusion power plant. On the way to such a prototype among others, there are two major challenges, which have to be addressed:

(a) A feasibility of an up-scaling of bulk samples smart alloy systems to the reactor-relevant sizes of several square centimeters.

(b) A possibility of joining of plasma-facing and a structural material. Smart alloy is a PFM, whereas the reduced-activation steels, Eurofer, Rusfer or Clam, as a structural material for a fusion power plant are currently under development in the Europe, Russia and China, respectively.

The results of joint pilot studies undertaken at Forschungszentrum Jülich GmbH (FZJ, Jülich, Germany), National Nuclear Research University MEPhI (Moscow, Russia) and at Hefei University of Technology (HFUT, Hefei, China) on the way of upscale of smart alloys for DEMO are described and analyzed in the manuscript.

\section{Up-scaling production of smart alloy}

\subsection{Experimental}

Up-scaling of smart alloys is an important activity on the way to industrial production. Since the data on the particular geometry of the first wall of DEMO remains scarce, we are aiming at reaching the dimensions planned for International Thermonuclear Experimental Reactor (ITER). There, the first wall will be castellated. The characteristic linear dimension of the beryllium first wall monoblock varies from about $20 \mathrm{~mm} \mathrm{[11]} \mathrm{to} 50 \mathrm{~mm}$ [12]. The rationale and the size of castellation originates from the evaluation of thermal loads and their inhomogeneity. Given the prospected heat loads in DEMO, it is expected that the geometry considerations will likely remain. However, the dimension of the currently produced SA bulk samples is $\emptyset 20 \mathrm{~mm}$ diameter with the thickness of up to $5 \mathrm{~mm}$, which cannot address fully the large-scale application in a future fusion power plant such as DEMO. Therefore, it is necessary to produce the large-size SA bulk samples.

Currently, the production of SA bulk samples for experiments is realized via MA followed by either hot isostatic pressing [13] or, since recently, by the field-assisted sintering technology (FAST) [10]. Based on the previous work [8] and on the current understanding, SA bulk samples with high density, fine grains and homogeneous structures have an excellent oxidation resistance. Aiming at this target, several challenges exist for up-scaling production of SA bulk samples using the current facilities. Hot isostatic pressing (HIP) was performed below solution temperature of SA, which could achieve a fine grain microstructure but is accompanied with a lot of Cr-rich phases [13]. For FAST, a pulsed direct current-activated and pressureassisted sintering technique, the sintering process is determined by multi densification mechanisms of localized heating, Joule heating and surface cleaning [14, 15]. Furthermore, many parameters such as the heating rate, sintering temperature, pressure, holding time, vacuum influence the FAST densification process of SA. When changing the sample size, the current density, pressure, and atmosphere applied on the sample will change even without changing the principle FAST parameters. Therefore, the attainment of a high density, fine grains, homogeneous microstructure, and anti-oxidation properties of the large-scale bulk smart alloy similar to those of small SA sample cannot be made by the simple scaling of the FAST parameters to a new sample size. In this work, small-size $(\varnothing 13 \mathrm{~mm}$ and $\emptyset 20 \mathrm{~mm}$ ) SA bulk samples with high density, submicrongrain, and homogeneous structures were produced. After analyzing their densification process, a large-size SA bulk 
sample with $50 \mathrm{~mm}$ diameter was Zohm H, Angioni C, Fable E, Federici G, Gantenbein produced.

The homogenous SA powder was prepared by MA technique as reported in Ref. [16]. Then, the alloyed powder was packaged into a graphite die and consolidated by FAST using a manual sintering mode. To prevent the carbon reaction with SA during the FAST densification process, a molybdenum foil was placed in the inner surface of the graphite die. Before sintering, the chamber of the FAST facility was pumped to the pressure below $10 \mathrm{~Pa}$ and kept under continuous pumping for the entire sintering cycle. To achieve a similar density and microstructure of the SA samples with different sizes, the FAST densification parameters must be different. The small-size SA samples $(\varnothing 13 \mathrm{~mm}$ and $\emptyset 20 \mathrm{~mm})$ were performed in the Labox-350 FAST system manufactured by NJS Co., Ltd. The SA samples were heated at a rate of $\sim 120^{\circ} \mathrm{C} \cdot \mathrm{min}^{-1}$ up to $1150{ }^{\circ} \mathrm{C}$. The temperature was controlled by adjusting the current at a loading rate of $75 \mathrm{~A} \cdot \mathrm{min}^{-1}$. To remove the residual gas, the temperature at $600{ }^{\circ} \mathrm{C}$ was kept for 2-3 min during the heating stage. Meanwhile, the pressure was increased from 10 to $90 \mathrm{MPa}$. Then, the SA samples are cooled down without any holding time at the maximum temperature, similarly as described in Ref. [16]. In case of the large-size $(\varnothing 50 \mathrm{~mm}) \mathrm{SA}$ sample, the sintering was performed in the Labox-6020 FAST system manufactured by NJS Co., Ltd. It could provide a higher current, larger applied load, and higher pumping rate than those of the Labox-350 system. Nevertheless, the maximum pressure applied cannot exceed $50 \mathrm{MPa}$ due to safety considerations. The pressure was increased from the initial 20-50 MPa at the temperature reaching $800{ }^{\circ} \mathrm{C}$. Due to the lower pressure attainable of $50 \mathrm{MPa}$, the sintering peak-temperature was increased from 1150 to $1300{ }^{\circ} \mathrm{C}$ to achieve densification. The Labox-6020 FAST system can provide large enough current to support the heating rate of $\sim 120{ }^{\circ} \mathrm{C} \cdot \mathrm{min}^{-1}$. During the heating process of the large-size SA sample pumping mitigated the build-up of the in-chamber pressure due to the gas release from the sample. The temperature change during the FAST densification process was monitored using an optical pyrometer operated in the range from 570 to $2000{ }^{\circ} \mathrm{C}$. Notably, the temperature changes were reflected by the measurement of the outer surface temperature of these graphite dies. Therefore, graphite die with the different thickness would result in a different temperature difference between the displayed and actual temperature. The wall thickness of $\emptyset 13 \mathrm{~mm}, \emptyset 20 \mathrm{~mm}$ and $\emptyset 50 \mathrm{~mm}$ graphite dies are $18 \mathrm{~mm}$, $20 \mathrm{~mm}$ and $25 \mathrm{~mm}$, respectively. In addition, the following parameters (displacement, current, temperature) evolution curves were also monitored during the FAST densification process. After that, the density of the SA bulk samples was measured following the Archimedes technique. The fracture morphology of SA bulk samples was characterized by scanning electron microscopy (SEM).

\subsection{Results and discussion}

After FAST densification, the microstructure information of SA samples with diameter of $\varnothing 13 \mathrm{~mm}$ and $\emptyset 20 \mathrm{~mm}$ was obtained from their fracture morphologies as shown in Fig. 1. The corresponding photographs are inserted in the SEM images. A very fine and high density microstructure can be observed in these two SA bulk samples. Based on the fracture morphology of Fig. 1, the grain sizes of $\emptyset 13$ $\mathrm{mm}$ and $\emptyset 20 \mathrm{~mm}$ SA samples were measured by intercept method and were approximately $100 \mathrm{~nm}$. The density of SA samples was measured by Archimedes' principle. After calculation, the relative density of these two SA samples was approximately $98.5 \%$. Notably, there are some dark gray discontinuous grains observed from these fracture morphologies, which are attributed to the Cr-rich phase. From the previous work [17], the SA powder was completely alloyed and with homogeneous microstructure after milling $60 \mathrm{~h}$. Therefore, the Cr-rich phase could be possibly formed during the FAST densification process. The sintering peak-temperature of SA sample $\left(1150{ }^{\circ} \mathrm{C}\right)$ is below its solution temperature $\left(\sim 1556{ }^{\circ} \mathrm{C}\right.$ for $\left.\mathrm{W}-11.4 \mathrm{wt} . \% \mathrm{Cr}\right)$ [18]. For a solid-solution alloy, precipitation must have occurred while sintering is below its solution temperature. Therefore, $\mathrm{Cr}$-rich phases should be inevitable in case of the current FAST densification of SA samples.

Figure 1 shows that the bulk SA samples with a $\emptyset 13 \mathrm{~mm}$ and $\emptyset 20 \mathrm{~mm}$, which were compacted using the same sintering parameters, have a similar microstructure and density. It means that $\varnothing 13$ and $\emptyset 20 \mathrm{~mm}$ SA samples have experienced a similar densification process. Therefore, it is meaningful to study their densification processes for production of the larger-size SA bulk samples. Figure 2 shows evolution of the basic FAST parameters such as displacement, temperature and current density. From Fig. $2 a$ and $b$, it can be seen that the SA samples with different diameters of $\emptyset 13 \mathrm{~mm}$ and $\emptyset 20 \mathrm{~mm}$ have similar change trend on displacement before cooling. The densification change curves reflect the expansion of graphite punch and the shrinkage and/or expansion of the SA powder bed during FAST process. In the vicinity of the cooling stage, there exists an inflection point in the displacement curves as marked with dotted line, which outlines the change in the densification process from shrinkage to expansion. It indicates that the SA bulk samples cannot be densified further. The slight increase in displacement curve is mainly due to the expansion of the graphite punch [17]. The corresponding temperature at the inflection point was called the densification temperature (marked with a red dot), which is the displayed temperature. From Fig. $2 a$ and b, the displayed densification temperature of the $\emptyset 13 \mathrm{~mm}$ and $\emptyset 20$ 

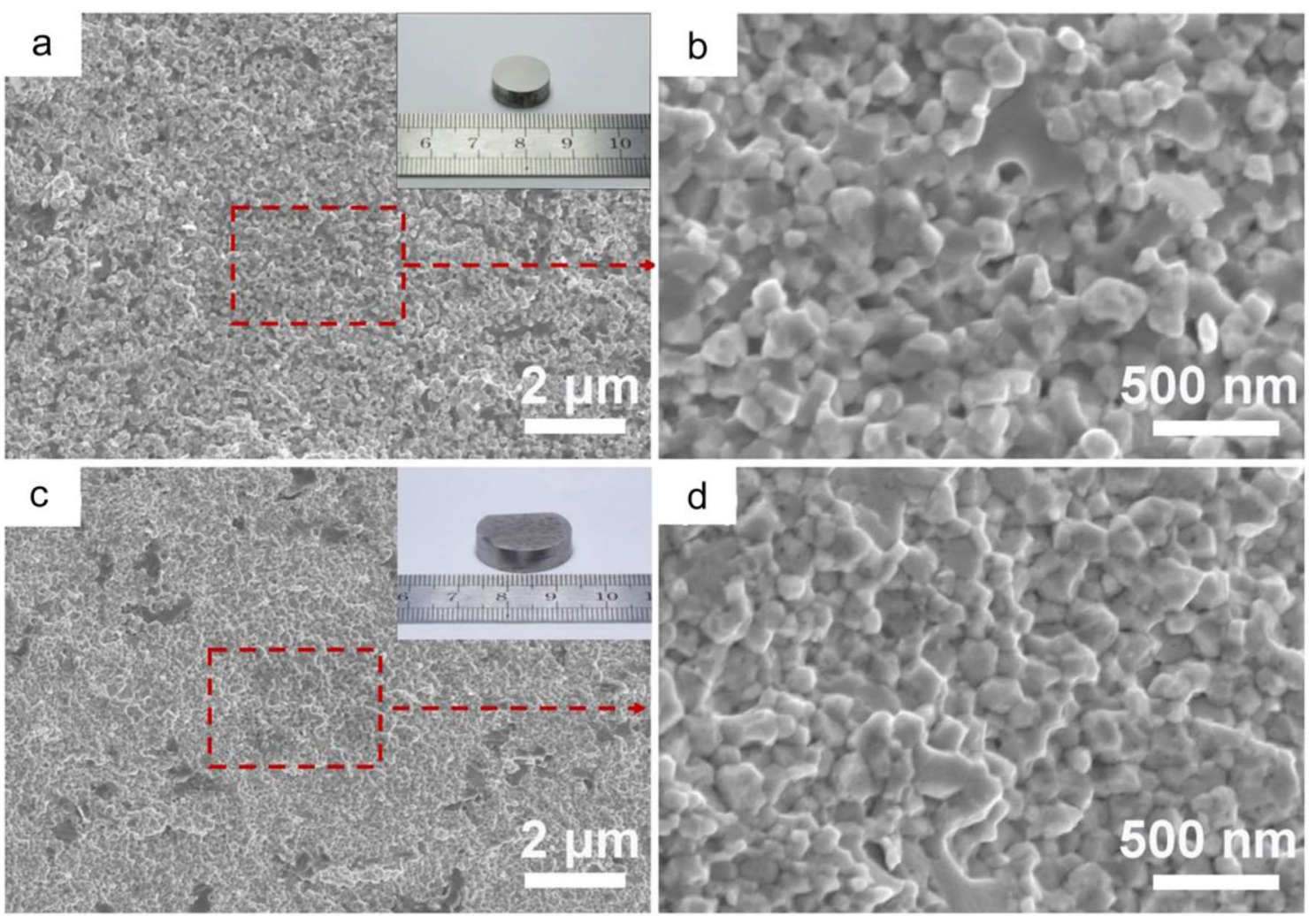

Fig. 1 Fracture morphology of SA samples with different diameter of a $\emptyset 13 \mathrm{~mm}$ and $\mathbf{c} \emptyset 20 \mathrm{~mm}$; the corresponding physical picture are also inserted. b, d Corresponding magnified views from the red-dotted rectangle

mm SA samples are $\sim 1100{ }^{\circ} \mathrm{C}$ and $\sim 1080{ }^{\circ} \mathrm{C}$, respectively. As mentioned previously, these two SA samples have similar density and microstructure, so their actual densification temperature should also be similar. Therefore, the difference in their displayed densification temperature is owing to the different wall thickness of the graphite die. The thicker graphite wall implies the farther distance from temperature detection position to the actual temperature measurement position and hence, the larger uncertainty.

Figure $2 \mathrm{c}$ and $\mathrm{d}$ show the temperature and current evolution curves of the SA samples with different diameters of $\emptyset 13 \mathrm{~mm}$ and $\emptyset 20 \mathrm{~mm}$ as a function of the sintering time, respectively. The current loaded on SA samples increases stepwise with the temperature change. Notably, the current loading has a slight difference: $\sim 105^{\circ} \mathrm{C} \cdot \mathrm{min}^{-1}$ for $\emptyset 13 \mathrm{~mm}$ and $\sim 130{ }^{\circ} \mathrm{C} \cdot \mathrm{min}^{-1}$ for $\emptyset 20 \mathrm{~mm}$ at the detected temperature range from $700{ }^{\circ} \mathrm{C}$ to the sintering peak-temperature. This is owing to a different current density loaded on the SA samples with different diameters under the same current loading manner. Further, the different heating rates for the SA samples were also the reason that results in the different sintering time. In addition, the maximum current density at $1150{ }^{\circ} \mathrm{C}$ for the SA sample with a diameter of $\varnothing 13$ $\mathrm{mm}$ is higher than that for the SA sample with a diameter of $\emptyset 20 \mathrm{~mm}$. The small graphite die $(\varnothing 13 \mathrm{~mm})$ with a thin wall means a high heat dissipation compared with that of the large graphite die $(\emptyset 20 \mathrm{~mm})$. Therefore, it requires a higher density current for supporting its heat dissipation during FAST process. In the FAST system, the current flows though the graphite punch and conductive SA material and generates heat (Joule heating effect), which heats the sample. Actually, the resistance of graphite is higher than that of the SA bulk samples [16]. Higher resistance means higher current-induced Joule heat. Therefore, the heat used for the consolidation of the SA samples was mainly derived from the thermal conduction of graphite punches. Simultaneously, there is also a heat dissipation by thermal irradiation during the FAST densification process. Different dimensions of graphite die/punch mean a different condition of heat dissipation. Naturally, it is also the reason for the different required time to heat the SA system up to the detected temperature of $570{ }^{\circ} \mathrm{C}$. In addition, the $\emptyset 20 \mathrm{~mm}$ SA sample with more powder mass than that of $\emptyset 13 \mathrm{~mm}$ SA sample would contain a larger amount of residual adsorbed gas, and therefore the temperature at $600{ }^{\circ} \mathrm{C}$ was kept for a longer time ( $3 \mathrm{~min}$ ) to remove the residual gas during the heating stage.

Based on the above cases, when increasing the SA sample diameter, the changes in the current density, heating rate, display densification temperature, and heat dissipation condition, should be considered to obtain SA bulk samples with 

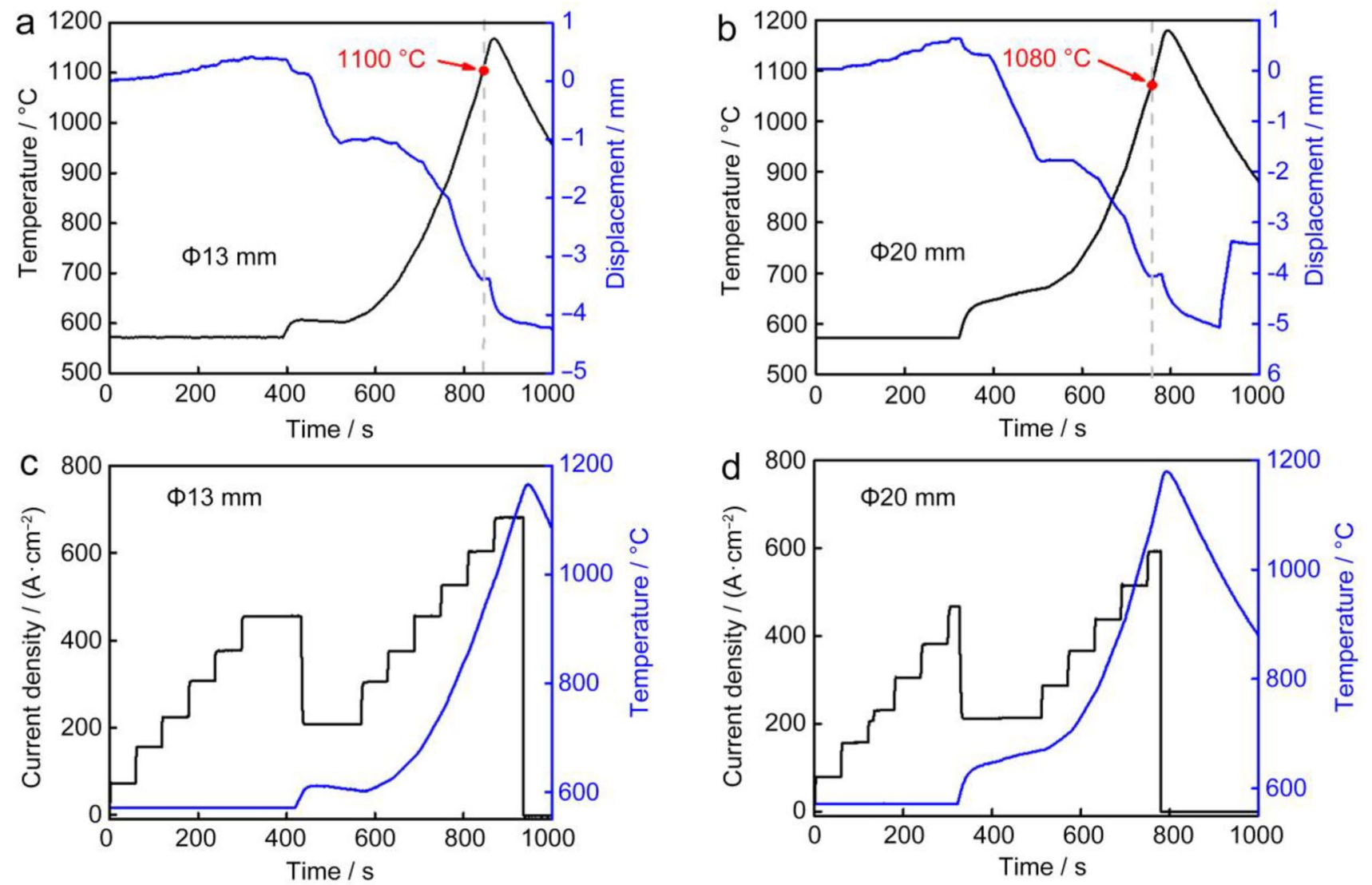

Fig. 2 Temperature and displacement evolution curves of SA samples as function of the time $\mathbf{a} \emptyset 13 \mathrm{~mm}, \mathbf{b} \emptyset 20 \mathrm{~mm}$; the temperature and current density evolution curves of SA samples as function of the time $\mathbf{c} \emptyset 13 \mathrm{~mm}, \mathbf{d} \emptyset 20 \mathrm{~mm}$

a similar density and microstructure. Based on the current understanding of the above factors and on the pressure limitation of the Labox-6020 FAST system, densification of the SA sample with a diameter of $\varnothing 50 \mathrm{~mm}$ was achieved by changing the sintering peak-temperature and the pressure.
The loading current evolution as a function of the sintering time is shown in Fig. 3a. It demonstrates that the heating rate is approximately $120^{\circ} \mathrm{C} \cdot \mathrm{min}^{-1}$ at the temperature ranges of $570 \sim 1300{ }^{\circ} \mathrm{C}$. Compared with the current density required for the densification of small-size SA samples $(\varnothing 13$
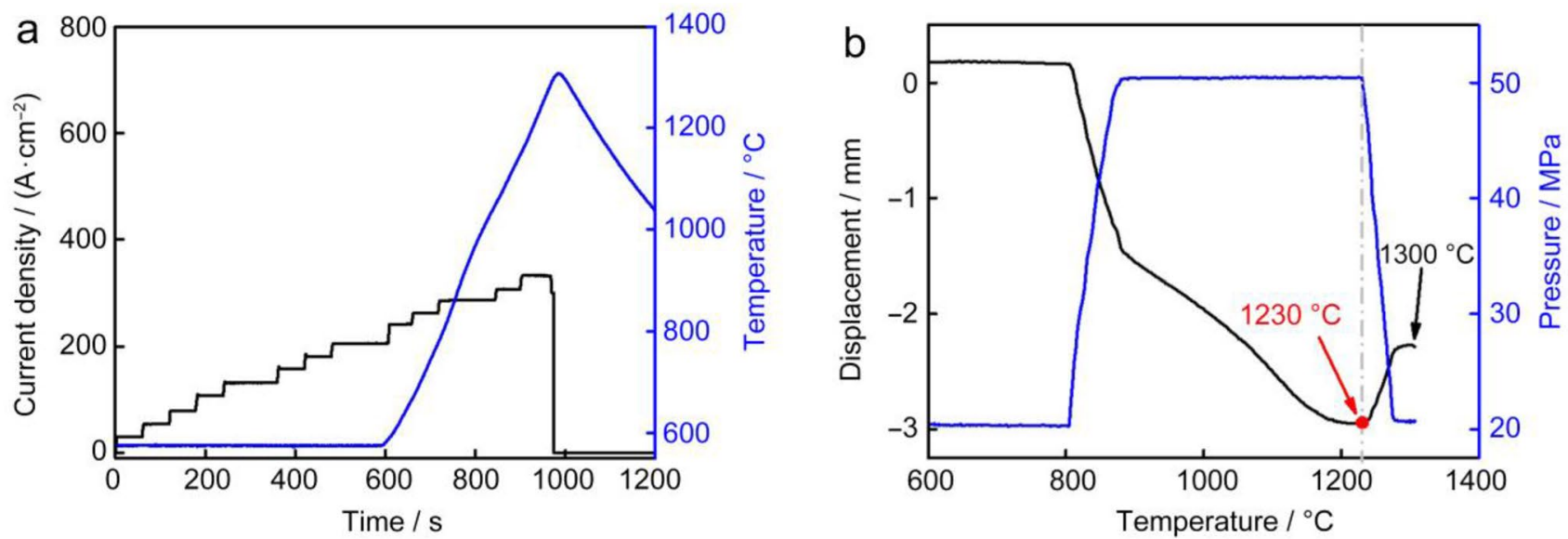

Fig. 3 a Temperature and current evolution curves of the SA sample with a diameter of $\varnothing 50 \mathrm{~mm}$ as function of the time; $\mathbf{b}$ Corresponding displacement and pressure evolution curves as a function of the temperature 
$\mathrm{mm}$ and $\emptyset 20 \mathrm{~mm}$ ), the required current density of SA sample with a diameter of $\varnothing 50 \mathrm{~mm}$ obviously decreases. Figure $3 \mathrm{~b}$ shows the corresponding displacement and pressure evolution curves as function of the sintering temperature. It is shown that in the displacement change curve, the SA powder bed has an obvious shrinkage when the pressure was evenly loaded from 20 to $50 \mathrm{MPa}$. After the pressure loading, the displacement continues to decline, which is derived from the densification of the SA sample. Notably, there exists a displacement plateau when the temperature ranges from $\sim 1200$ to $\sim 1230{ }^{\circ} \mathrm{C}$. The displacement plateau indicates that the $\emptyset 50 \mathrm{~mm}$ SA sample almost reached the highest possible density at the mentioned FAST conditions. Actually, the temperature of $\sim 1230{ }^{\circ} \mathrm{C}$ is still below the expected densification temperature of the $\emptyset 50 \mathrm{~mm}$ SA sample. Considering these two factors, the temperature required for sintering densification and preventing grain growth, the $\emptyset 50 \mathrm{~mm}$ SA sample was continuously heated to $1300{ }^{\circ} \mathrm{C}$ but under a lower pressure of $20 \mathrm{MPa}$. According to Ref. [18], sintering at a high temperature but under a low pressure could avoid grain growth. The displacement increases rapidly as the temperature reaches the temperature of above $1230{ }^{\circ} \mathrm{C}$. The pressure then was quickly decreased from 50 to $20 \mathrm{MPa}$. Furthermore, compared with the small-size SA samples $(\varnothing 13 \mathrm{~mm}$ and $\emptyset 20 \mathrm{~mm})$, the $\varnothing 50 \mathrm{~mm}$ SA sample possess a high densification temperature $\left(>1230^{\circ} \mathrm{C}\right)$. The main reason would be that the $\varnothing 50 \mathrm{~mm}$ SA sample was merely loaded with a low pressure of $50 \mathrm{MPa}$.

Figure 4 shows the fracture morphology of the large-size SA sample $(\varnothing 50 \mathrm{~mm})$ and its photograph after FAST densification. No noticeable cavities and/or pores can be observed and the relative density reached up to approximately $98.5 \%$. Compared with Fig. 1, there are no dark gray discontinuous grains, as shown in Fig. 4. This result indicates that a large-sized SA sample with high density and homogenous microstructure was obtained under the current FAST sintering parameters. Notably, the homogenous microstructure was attained for the large-size SA sample, but not for the small-size ones $(\varnothing 13 \mathrm{~mm}$ and $\emptyset 20 \mathrm{~mm})$. This should be due to the fact that the actual sintering temperature reaches up to or even exceeds its solution temperature, so the actual sintering peak-temperature of the large sample is higher than that of small-size SA sample. The actual sintering peaktemperature must be higher than the measured sintering peak-temperature because there exists a distance between the sample position and the temperature detection position. Due to the higher temperature, $\mathrm{Cr}$ precipitation during the FAST densification of the $\emptyset 50 \mathrm{~mm}$ SA sample was avoided.

The grain size of the SA sample was measured to be approximately $300 \mathrm{~nm}$, as shown in Fig. $4 \mathrm{~b}$. The grain size is larger than that of small-size SA samples sintered at $1150{ }^{\circ} \mathrm{C}$ $(\sim 100 \mathrm{~nm})$. The grain growth is induced by the thermal activation energy at the high temperature [19], but the grain size is still within the acceptable submicron range.

The obtained positive results on up-scaling of the SA samples to the DEMO-relevant sizes allow the next step in realizing the mockup of the first wall-the joining of the smart alloy to the structural material. The results of the pilot joining tests are reported in the next section.

\section{Pilot studies on joining of smart alloys with structural materials}

\subsection{Experimental}

The common way to join complex elemental systems is brazing - the widespread technology used in nuclear [20, 21], aerospace [22] and automotive [23, 24] industry. This technology is also used in the manufacturing process of ITER
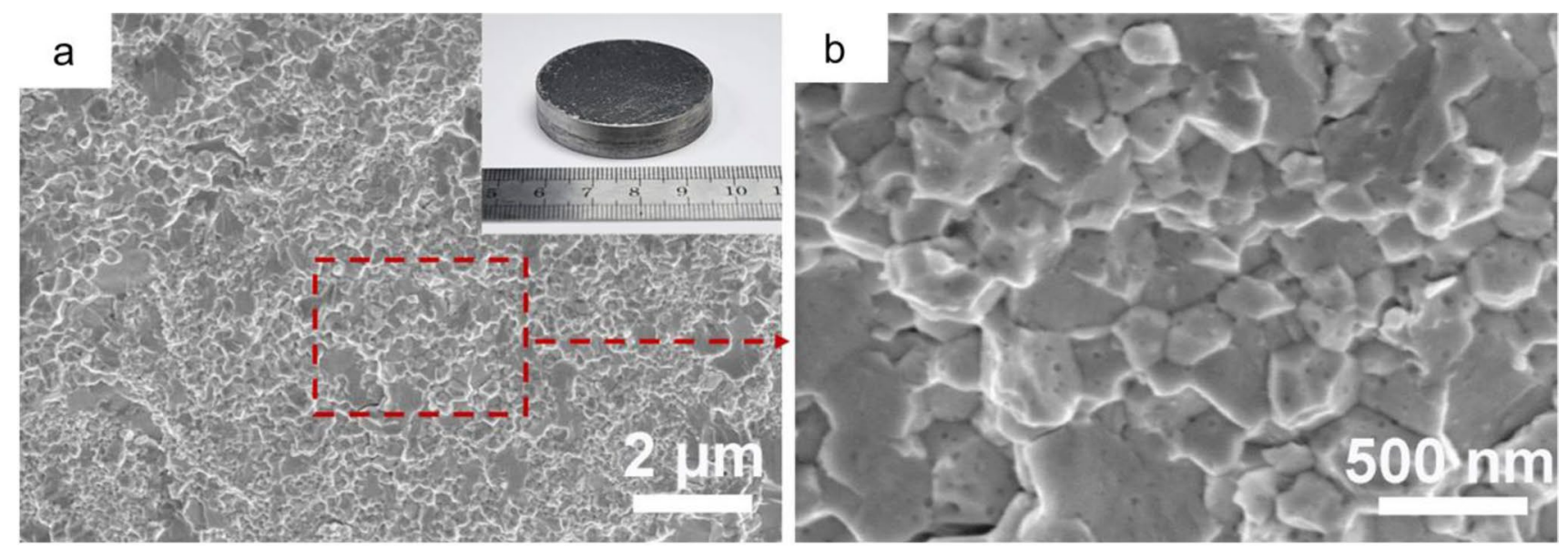

Fig. 4 a Fracture morphology of SA sample with a diameter of $\emptyset 50 \mathrm{~mm}$ and the corresponding physical picture; $\mathbf{b}$ Magnified view from the reddotted rectangle 
components [25, 26]. Brazing has several beneficial aspects: it does not require high pressure and is cheaper than that in i.e. hot isostatic pressing (HIP). Moreover, as the number of armoring tiles in plasma-facing components is rather high, replacement of defective tiles after manufacturing are needed. Brazing is beneficial from this point of view [27] since it allows for a local replacement of a particular damaged component. For this purpose, filler alloys in a form of foils are convenient, but the composition of such alloys should consist of reduced-activation elements only because of the requirement for the DEMO materials. Presently, there is no filler alloy consisting of low-activation elements only. Nickel [28] or copper [29]-based alloys are frequently used. In this study, we have applied a brazing alloy with an appropriate composition even without $\mathrm{Cu}$.

The rapidly-solidified into foil Titanium-ZirconiumBeryllium brazing alloy with the following composition was used: $48 \mathrm{Ti}-48 \mathrm{Zr}-4 \mathrm{Be}$ wt.\%. The foil possesses always high quality, because after rapid solidification, due to high glass forming ability [30], the alloy is amorphous with a small amount of crystalline phase [31]. The chemical elements are considered as reduced-activation [32]. The thickness of the brazing alloy was $70 \mu \mathrm{m}\left(T_{\text {solidus }} \approx 850^{\circ} \mathrm{C}\right)$. SA samples with dimensions of $5 \times 5 \times 4 \mathrm{~mm}^{3}$ were supplied by Forschungszentrum Jülich $\mathrm{GmbH}$. The bulk SA samples were produced via MA and compacted using FAST. The manufacturing details can be found in e.g. Ref. [8]. For structural material the reduced-activation ferritic-martensitic (RAFM) RUSFER steel [33] in the initial ferritic state was used (iron $(\mathrm{Fe})-12$ chromium $(\mathrm{Cr})-2$ tungsten $(\mathrm{W})$-vanadium $(\mathrm{V})$ tantalum (Ta)-boron (B), wt \%). Samples had dimensions of $7 \times 7 \times 4 \mathrm{~mm}^{3}$. The scheme of a typical specimen for brazing is presented in Fig. 5. It is known that a direct joint between tungsten and steel is impossible due to the different coefficients of thermal expansion (CTE) which causes damage to the joint even after the manufacturing process [34, 35]. To decrease thermal stresses responsible for a damage, the usage of interlayers is preferable. Ta and V efficiently reduce stresses to be occurred in tungsten [35]. In this work, pure Ta with the thickness of $200 \mu \mathrm{m}$ and dimensions of $7 \times 7 \times 0.2 \mathrm{~mm}^{3}$ was chosen because it doesnot form brittle eutectic with components of the filler alloy, apart from $\mathrm{V}$ forming the brittle eutectic with $\mathrm{Zr}[36,37]$.

The brazing process should not worsen the properties of the materials to be joined. Since that two brazing modes were used, where $T_{\mathrm{b}}$ is brazing temperature, $t$ is dwell time at $T_{\mathrm{b}}, V_{\mathrm{h}}$ is heating rate, and $V_{\mathrm{c}}$ is cooling rate:

Mode 1: $T_{\mathrm{b}}=950{ }^{\circ} \mathrm{C}, t=30 \mathrm{~min}, V_{\mathrm{h}}=40{ }^{\circ} \mathrm{C} \cdot \mathrm{min}^{-1}$, $V_{\mathrm{c}}=20^{\circ} \mathrm{C} \cdot \mathrm{min}^{-1}$. This mode was chosen to be sure that properties of the SA will remain the same after brazing. It was previously shown that the oxidation resistance of the alloy degrade at a temperature higher than $1000{ }^{\circ} \mathrm{C}$ [4], where microstructural changes could have been the reason.
Fig. 5 Scheme of the investigated brazed joints

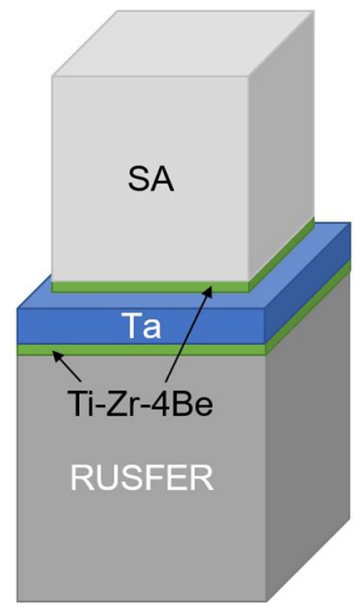

Mode 2: The first step is heating up to $T_{\mathrm{b}}=1100^{\circ} \mathrm{C}$ with dwell time $t=60 \mathrm{~min}, V_{\mathrm{h}}=40^{\circ} \mathrm{C} \cdot \mathrm{min}^{-1}, V_{\mathrm{c}}=20^{\circ} \mathrm{C} \cdot \mathrm{min}^{-1}$. The second step is aging at $T=720{ }^{\circ} \mathrm{C}, t=180 \mathrm{~min}$, $V_{\mathrm{h}}=20^{\circ} \mathrm{C} \cdot \mathrm{min}^{-1}, V_{\mathrm{c}}=10^{\circ} \mathrm{C} \cdot \mathrm{min}^{-1}$. This mode was chosen to make a thermal treatment of the steel, and this mode is called "to traditional heat treatment" (THT) of RUSFER in the sense of Ref. [38].

The mode 2 was applied to study a possibility of simultaneous brazing and heat treatment of RAFM steel and SA. It should be noted that the application of any manufacturing process to make a joint should take into account the final microstructural state of the base materials, since it should not alter the principal properties of the materials to be joined. However, this fact is often not taken into consideration [39].

After a brazing cycle, microstructural investigations of the brazed joints were carried out using ZEISS EVO 50 XVP scanning electron microscope equipped with energy dispersive spectroscopy (EDS) INCA X-ACT and wavelengthdispersive spectroscopy (WDS) INCA Wave 500. WDS was used to measure yttria concentration. Neither EDS nor WDS could identify Be, because its concentration was very low. Other elements were measured by EDS, as well as concentration profiles.

A thermocycling test (TC) was applied to analyze the reliability of the joint. The thermocycling comprised heating to $600{ }^{\circ} \mathrm{C}$ and cooling to $300{ }^{\circ} \mathrm{C}$ according to the water-cooled lithium-lead (WCLL) blanket concept. The DEMO reactor operation implies pulse and dwell periods. It is known that the operation temperature of the RAFM steel is limited by $550{ }^{\circ} \mathrm{C}$ because of the drop in properties [40-42]. Hence the temperature during the pulse period will not exceed $550{ }^{\circ} \mathrm{C}$ on a steel surface [43]. However, the temperature expected in a brazed joint can be even higher. Therefore, $600{ }^{\circ} \mathrm{C}$ has been chosen as upper temperature of the TC. The lower temperature of $300{ }^{\circ} \mathrm{C}$ was chosen because during the dwell period, the temperature of a brazed joint should be close 
to the coolant and during the dwell period the coolant will continue to flow [44]. Every 20 cycles, an appearance of the specimen was examined by macro examination at sevenfold magnification with binocular microscope. Only the specimen obtained using the brazing mode 1 was used in the experiment because the structure of the SA was preserved in its initial state. The details will be reported later in this paper. The specimen was placed into quartz ampoule connected to a vacuum pump obtaining $p=1 \mathrm{~Pa}$. The specimen in the ampoule was heated up to $600{ }^{\circ} \mathrm{C}$ without dwelling, and then the ampoule was taken out of the furnace and the specimens were cooled down to $300{ }^{\circ} \mathrm{C}$. The temperature of the specimen was controlled by $\mathrm{Cr}-\mathrm{Al}$ thermocouple, which was inserted into the ampoule. This thermocycle corresponds to $V_{\mathrm{h}}=4{ }^{\circ} \mathrm{C} \cdot \mathrm{s}^{-1}$ and $V_{\mathrm{c}}=2{ }^{\circ} \mathrm{C} \cdot \mathrm{s}^{-1}$. In total, a hundred thermocycles were applied.

\subsection{Results}

\subsubsection{Microstructure studies}

The microstructure of the SA far from a seam was investigated before and after brazing. The initial state of SA is presented in Fig. 6a, after brazing mode 1 in Fig. 6b, and after brazing mode 2 in Fig. 6c. The initial microstructure consists of tungsten (W) - based solid solution with chromium ( $\alpha \mathrm{W}, \mathrm{Cr})$, chromium $(\mathrm{Cr})$ - based solid solution with $\mathrm{W}(\alpha \mathrm{Cr}, \mathrm{W})$, yttria- $(\mathrm{Y}-\mathrm{O})$. The microstructure is similar to those observed in Ref. [45]. No evident microstructure changes occurred after mode 1 . After mode 2 decay in $\mathrm{Cr}-$ based phase occurred into $(\alpha \mathrm{W}, \mathrm{Cr})$ and $(\alpha \mathrm{Cr}, \mathrm{W})$, according to a phase diagram [46]. It is known that fine distribution of $\mathrm{Y}-\mathrm{O}$ precipitates along nanograin's boundaries occur in the SA [8], and we also identifies larger ones in Fig. 6. We see that after mode 2 (Fig. 6c) the density of the large $\mathrm{Y}-\mathrm{O}$ precipitates increased, which can be related to coarsening of the smaller precipitates.

Figure 7 shows the microstructure of the joints at interface to SA. A thick diffusion layer was formed; however, the thickness after different brazing modes is different. The seams are divided into two areas: A—interface, B-diffusion layer.

According to the concentration profiles (plotted on the micrograph, Fig. 7a) measured by EDS at $20 \mathrm{keV}$ for the sample produced using the mode 1 , the concentration of chromium does not decrease significantly towards the interface. $\mathrm{Ti}$ and $\mathrm{Zr}$ follow the common law of diffusiondescending concentration from the seam to the bulk of the SA. The peaks of $\mathrm{Zr}$ and Ti within layers III and IV show that not all the brazing alloys melt when they interact with these base materials. Ta does not diffuse into SA. No diffusion of any component into pure Ta occurred.

Concentration profiles for the sample produced using the mode 2 (plotted on the micrograph, Fig. 7b) are quite different. The amount of $\mathrm{W}$ and $\mathrm{Ta}$ decreases gradually from one base material to another. Whereas Ta diffuses noticeably into $\mathrm{W}, \mathrm{W}$ does not do the same. $\mathrm{Zr}$ and Ti profiles are different from those in the sample produced using the mode 1: the concentration of Ti has a drop within layers II and III, but descends gradually beyond these layers; $\mathrm{Zr}$ profile has a significant drop within layers III and IV (Fig. 7b, d). This can be related to different coefficients of diffusion of $\mathrm{Zr}$ in $\mathrm{W}$ and $\mathrm{Cr}$; however, there is no valid data on diffusion coefficients that are available. This is also a result of the full interaction between the brazing alloy melt and the base materials.

The detailed investigation of the area $\mathrm{A}$ is shown in Fig. $7 \mathrm{c}$ for the mode 1 and Fig. $7 \mathrm{~d}$ for the mode 2. The microstructures are considerably different. Five layers were formed in sample produced using the mode 1 (Fig. 7c): (I) Needle-like $74 \mathrm{Ta}-16 \mathrm{Ti}-6 \mathrm{Cr}-3 \mathrm{Zr}-1 \mathrm{~W}$ at.\% phase (Magnified image of the layer is shown in Fig. 8a); (II) Mechanical mixture of 70Ta-20Ti-5W-3Zr-2Cr at.\% and Ti-based phase; (III) 49Ta-26Ti-17W-7Zr-2Cr at.\% phase formed within Ti-based phase; (IV) 67Ti-19Zr-6Ta-5,5Cr-2,5Ta at.\% phase; (V) Two Ti-W phases formed within Ti-based phase and SA, magnified image of the layer is shown in Fig. 8b.

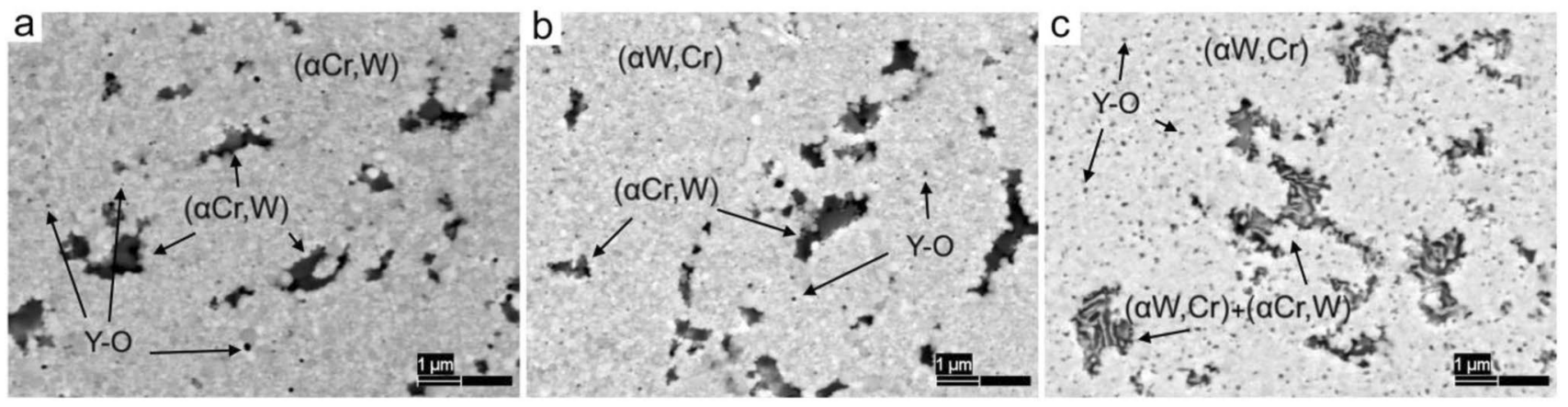

Fig. 6 Microstructure of a bulk SA: a initial, $\mathbf{b}$ after brazing at a mode 1, $\mathbf{c}$ after brazing at a mode 2 
Fig. 7 SEM images of the Ta/ SA seams: Sample produced using the mode 1: a full view with concentration profiles and marked areas: A - interface; B1, B2-diffusion layer; c magnified view of the area $A$ with marked layers, magnified images of the green and blue areas is shown in Fig. 8; Sample produced using the mode $2: \mathbf{b}$ full view with concentration profiles and marked areas: Ainterface; B1, B2-diffusion layer; $\mathbf{d}$ magnified view of the area A with marked layers
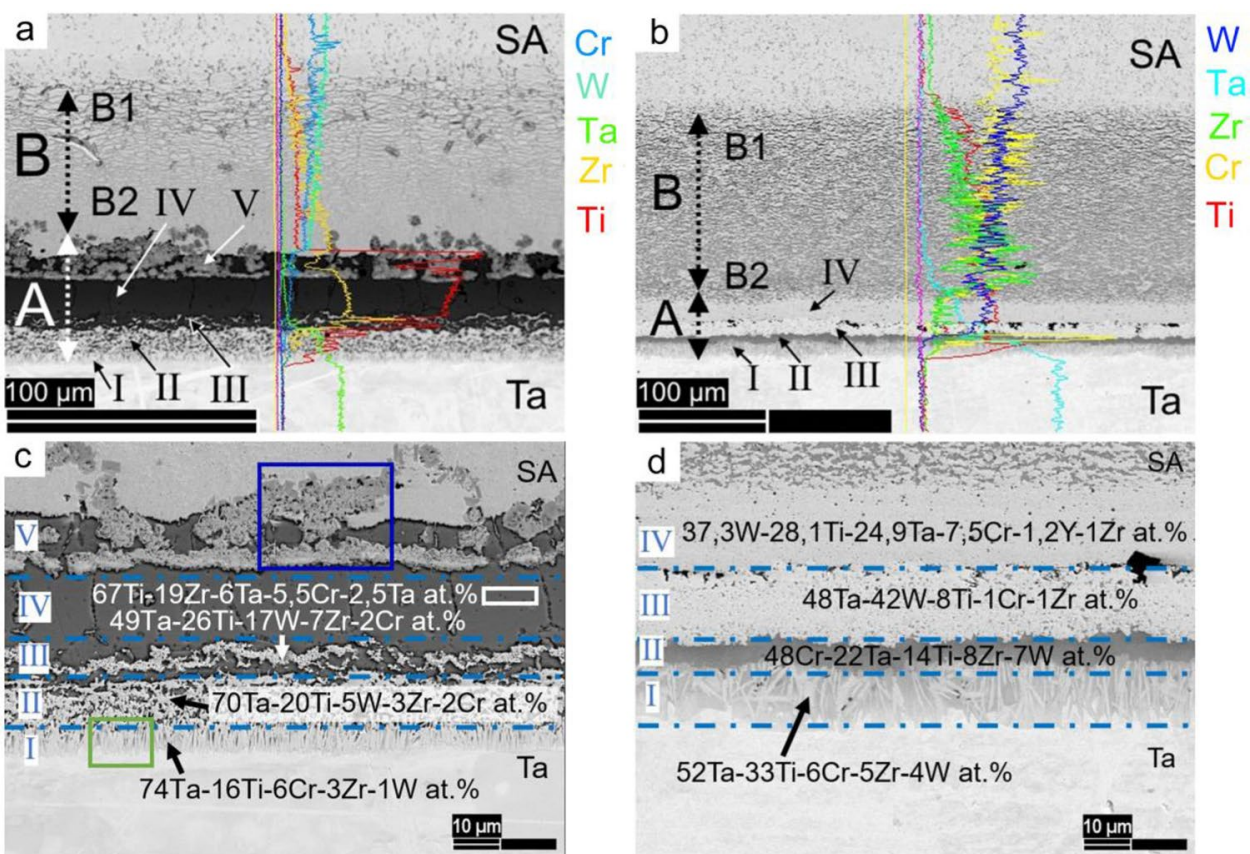

Though beryllium could not have been identified in the course of this study, we can assume that no beryllide formed as no black-contrast phases are observed. Layers I-III (Fig. 7c) represent Ta-based crystals formed within Ti-based solution, where Ti-based solution by its contrast should be like layer IV. Concentration of Ta decreases from I to III, while Ti increases.

In weight, the percentage composition of the layer IV is 48Ti-26Zr-15Ta-7W-4Cr wt.\%. Compared to the initial composition of the brazing alloy (47Ti-47Zr-4Be wt.\%) Zr more effectively dissolved than Ti due to deeper diffusion into SA (Fig. 7a). Also, bright-light phases within grains and on their boundaries were formed. Most of these phases fell out during grinding.

In the layer $\mathrm{V}$ shown in Fig. 8b, the two phase morphologies were found, which are marked as rectangular (43.3Ti-34.8W-11.5Cr-8Ta-2.4Zr-0.1Y at. \%) and hexagonal (41.9Ti-36.4W-9Ta-7.6Cr-5Zr-0.3Y at.\%) outlined. The former preferably grows within SA, and the latter within Ti-based phase.

Four layers were formed in the sample produced using mode 2 in the area A (Fig. 2d): (I) needle-like $52 \mathrm{Ta}-33 \mathrm{Ti}-6 \mathrm{Cr}-5 \mathrm{Zr}-4 \mathrm{~W}$ at.\% phase; (II) chromium-based $48 \mathrm{Cr}-22 \mathrm{Ta}-14 \mathrm{Ti}-8 \mathrm{Zr}-7 \mathrm{~W}$ at. $\%$ phase; (III) corn-like
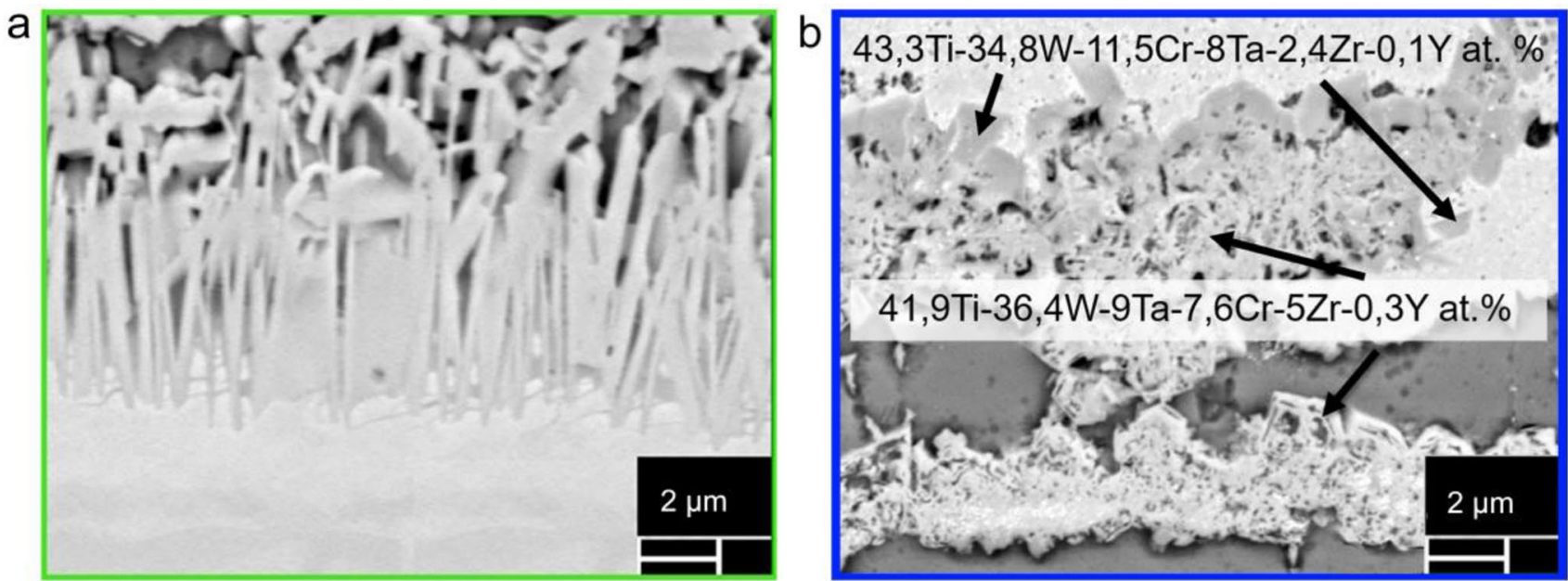

Fig. 8 Magnified SEM images of the layers outlined in Fig. 7c of the sample produced using the mode 1: a green rectangle outline-layer I; $\mathbf{b}$ blue rectangle outline-layer $\mathrm{V}$ 
48Ta-42W-8Ti-1Cr-1Zr at.\% phase; (IV) smooth layer of the following composition $37.3 \mathrm{~W}-28.1 \mathrm{Ti}-24.9 \mathrm{Ta}-7.5 \mathrm{Cr}$ $-1.2 \mathrm{Y}-1 \mathrm{Zr}$ at. $\%$.

The layers are clearly divided from each other, because all of them are one-phase structured. No layers with a composition close to the initial composition of the brazing alloy formed. Layer II is enriched with $\mathrm{Cr}$, while layers III and IV are chromium depleted. Between layer III and IV crumbling is observed, probably due to the formation of the beryllium phase.

Magnified microstructure of the diffusion layers, area B pointed out in Fig. 7a, b, is presented in Fig. 9. The area is divided into two zones: B1 (Fig. 9a) and B2 (Fig. 9b), where B1 is closer to SA, and B2 is closer to Ta. Area B is divided into two zones because of the different morphologies, which is described further. The thickness of the diffusion layer in the sample produced using mode 1 is $80 \mu \mathrm{m}$, where B1 has a thickness of $20 \mu \mathrm{m}$ and $\mathrm{B} 2$ has a thickness of $60 \mu \mathrm{m}$. The thickness of the diffusion layer after mode 2 is $160 \mu \mathrm{m}$, where B1 and B2 have a thickness $80 \mu \mathrm{m}$. Decay into layers of $\mathrm{W}$-based and $\mathrm{Cr}$-based phases is observed both in B1 and B2. Though the thickness of the layers is different for the samples produced by two modes, their compositions are similar. In B1 zone, the composition of bright $\mathrm{W}$-based phase is equal to the initial composition of SA-68.9W-30Cr-1.1Y at.\% (or $88.4 \mathrm{~W}-10.9 \mathrm{Cr}-0.7 \mathrm{Y}$ wt.\%), whereas in B2, a W-based phase is significantly alloyed with Ti and Ta: 50W-28.9Ti-12Ta-8Cr-0.9Y at.\%. Dark Cr-rich phase is mainly alloyed with $\mathrm{Zr}$ and $\mathrm{W}$ both in B1 and B2 zones as it can be seen in Fig. 9. B1 also contains additional Cr-based phase with clear outlines. In the sample produced using mode 1 , additional $\mathrm{Cr}$-based phase has just started to grow and has a composition close to that of $\mathrm{Cr}$-rich phase. In the sample produced using mode 2, the phase takes a distinct form and has higher $\mathrm{W}$ concentration, because dissolution of the inner W-based phase occurred. These phases were not observed in the area B2. That is why the diffusion layer was divided into two zones.

Figure 10 shows microstructure with EDS maps of the joints at RUSFER/Ta interface: $\mathrm{a}$-mode 1 ; $\mathrm{b}$-mode 2 . No pores or cracks were observed. Probably not the whole amount of the molten brazing alloy dissolved with the base material, which resulted in a solidification of residual brazing alloy. The area of the residual brazing alloy is marked with an arrow in Fig. 10. A lower amount of residual brazing alloy was left in the mode 2 sample due to higher brazing

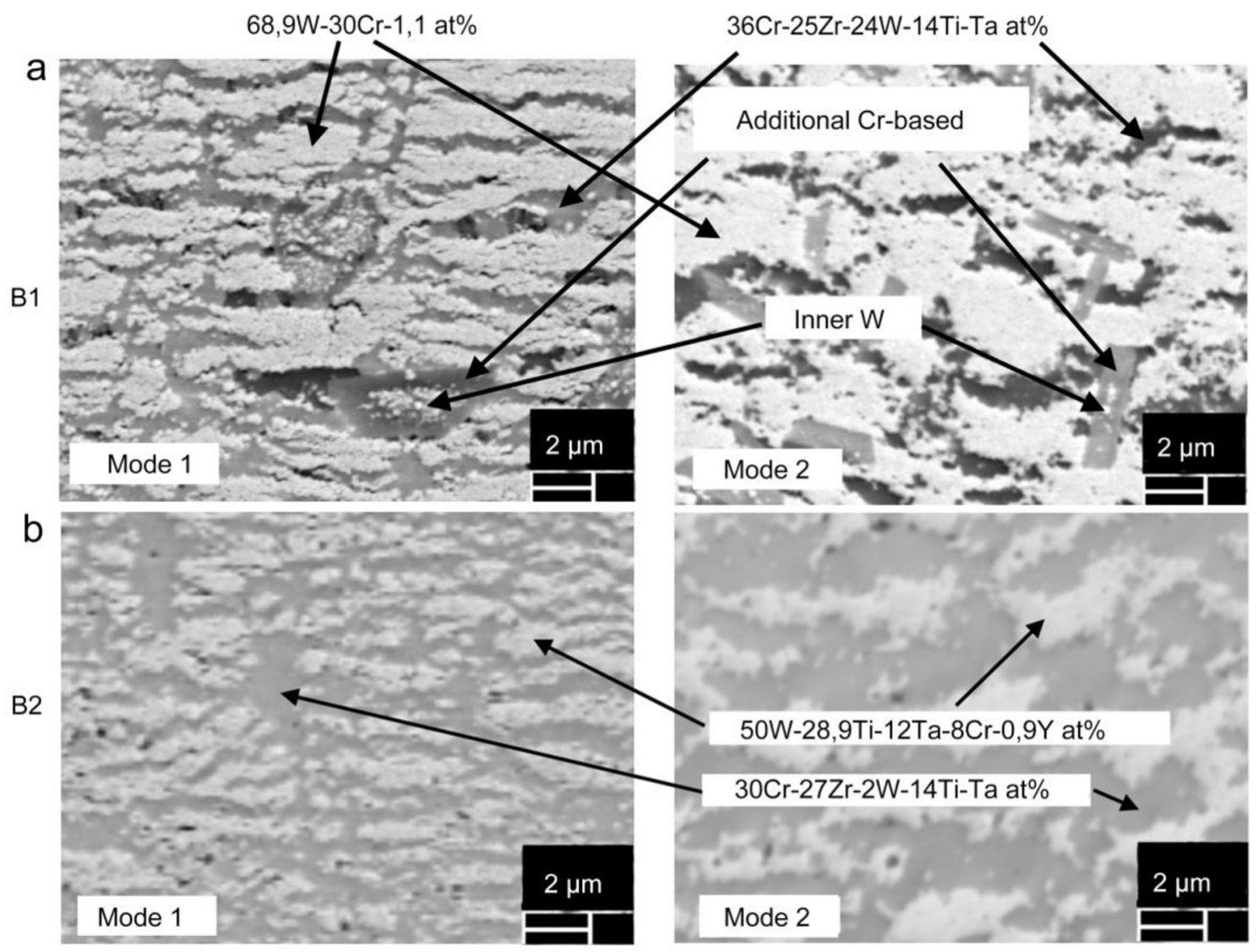

Fig. 9 SEM images of a diffusion layer B in the sample produced using modes 1 and 2: a B1 zone; b B2 zone 
temperature, and everything else is similar. Bright needles correspond to Ta-rich phase. Since the mode 2 is equivalent to the traditional heat treatment of RUSFER, it is important to investigate the microstructure of a steel. Figure 11 shows the microstructure of the RUSFER near the brazed seam. Martensitic phase has been formed in the bulk alloy; a thin ferritic layer was formed near the brazed seam. As this work is aimed at detailed investigations of the $\mathrm{SA}, \mathrm{Ta} /$ steel joint investigation will be presented elsewhere.

According to the microstructural investigations, only the sample produced using mode 1 was selected to conduct TC, because the initial microstructure of the SA was preserved and no crumbling occurred.

\subsubsection{Thermal cycling}

The microstructure of the specimen after TC is presented in Fig. 12. No detachment at both interfaces was observed using macro examination and SEM. The thickness of the diffusion layer at the Ta/SA interface (area B in Fig. 12a) grew from $80 \mu \mathrm{m}$ before thermocycling to $150 \mu \mathrm{m}$, where $\mathrm{B} 1$ had a thickness of $50 \mu \mathrm{m}$ and B2 of $100 \mu \mathrm{m}$. Magnified microstructure of the area $\mathrm{A}$ of the Ta/SA seam is presented in Fig. 12b. The thickness of the layer I increased: a new needle-like phases grew within Ta. Evidently, iron (Fe) diffusion occurred during thermocycling, as the presence of $\mathrm{Fe}$ in the amount of 1 at.\% in the layers IV and V was observed.
Diffusion could have gone through Ta interlayer or more likely through the fillet regions, as the brazing alloy wetted the whole Ta interlayer, which is shown in Fig. 12c. Ta-Wbased crystals formed within hexagonal Ti-W phase layer $\mathrm{V}$. These crystals have crisp boundaries. As it can be seen from the SEM image crumbling close to these crystals occurred (Fig. 12b).

\subsection{Discussions}

Brazing of SA with RUSFER was successfully carried out with the use of Ta interlayer and $47 \mathrm{Ti}-47 \mathrm{Zr}-4 \mathrm{Be}$ wt. $\%$ brazing alloy. Heating of the SA up to $950{ }^{\circ} \mathrm{C}$ does not change the microstructure; however, brazing at higher temperatures up to $1100{ }^{\circ} \mathrm{C}$ leads to decay of the $\mathrm{W}-\mathrm{Cr}$ solution.

As shown in Sect. 3.2, a thick diffusion layer was formed between Ta and SA. This fact claims good inter-diffusion of the brazing alloy and the SA. Due to the full dissolution of the brazing alloy when using mode 2 a thicker diffusion layer was formed. This layer represents decay of $\mathrm{W}-\mathrm{Cr}$ alloy into layer-by-layer W-based and Cr-based solid solutions. Closer to the bulk SA composition of the W-based solid solution is similar to the initial SA alloy composition. Closer to the seam brazing alloy elements dissolved in the solid solutions: $\mathrm{Zr}$ mainly dissolved in $\mathrm{Cr}$, and $\mathrm{Ti}$ in $\mathrm{W}$. In the mode 2 sample an additional rectangle Cr-based phase formed, whereas in the mode 1 sample this phase has just started to form
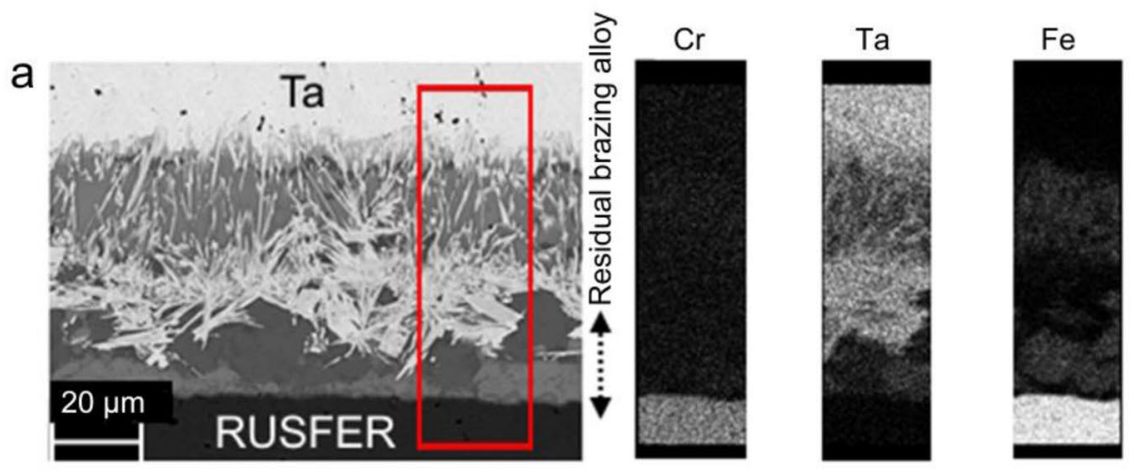

b

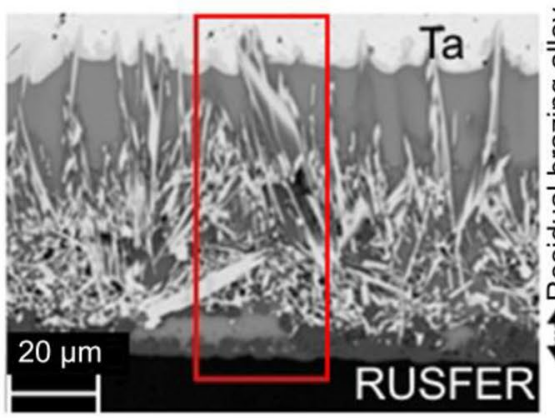

$\mathrm{Cr}$

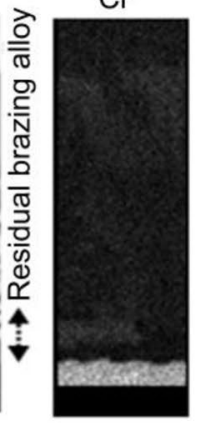

Ta

$\mathrm{Fe}$
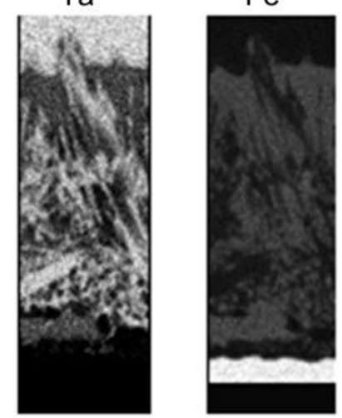
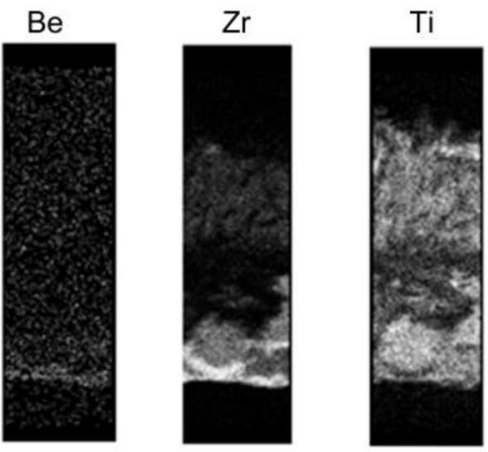

$\mathrm{Be}$

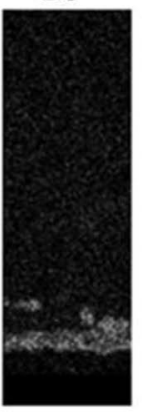

$\mathrm{Zr}$

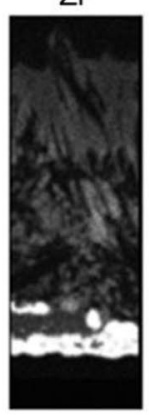

$\mathrm{Ti}$

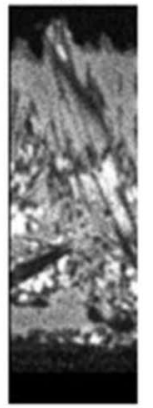

Fig. 10 SEM images and EDS maps of RUSFER/Ta brazed seam: a Mode 1. Red rectangle outlines EDS maps areas are shown on the right; $\mathbf{b}$ Mode 2. Red rectangle outlines EDS maps areas are shown on the right 
Fig. 11 SEM image of RUSFER near brazed seam after brazing at the mode 2

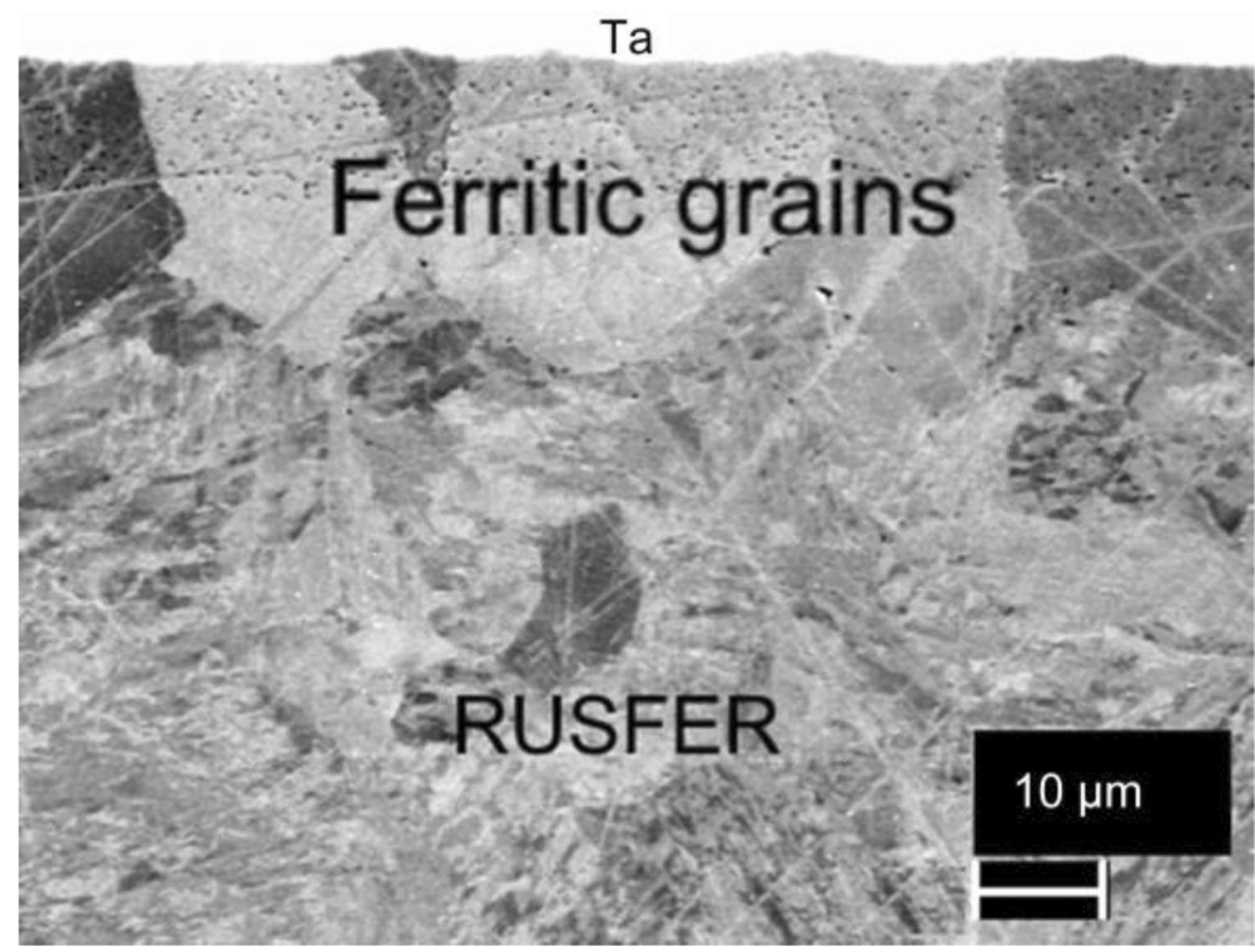

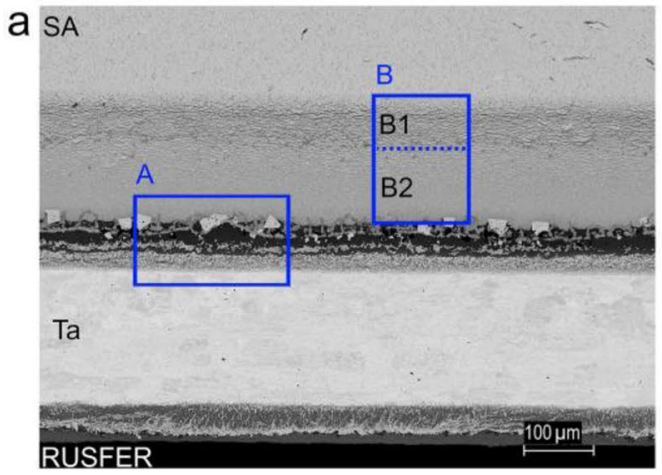

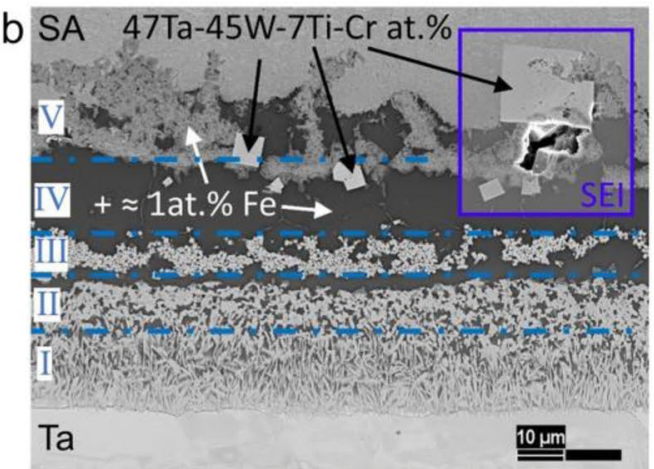

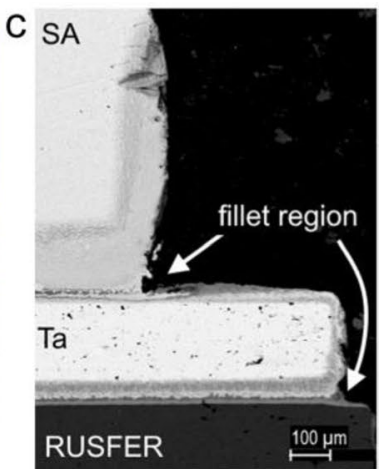

Fig. 12 SEM image of the RUSFER/Ta/SA brazed joint obtained by Ti-Zr-4Be using brazing mode 1 after TC: a full view; $\mathbf{b}$ magnified view of area A with marked layers; $\mathbf{c}$ fillet region

(Fig. 9). Similar layer-by-layer structure was also observed in Ref. [47].

Significantly different microstructures of the $\mathrm{Ta} / \mathrm{SA}$ seam using two brazing modes were detected (Fig. 7); however, the only difference in the RUSFER/Ta seam is the thickness of residual amount of the brazing alloy (Fig. 10).

Some common features were observed for samples made using the mode 1 and 2 especially at the interface from Ta to the smart alloy (Fig. 7). The morphology of the layers marked as I is similar in both specimens. The microstructure of the layer correlates with results was presented in Ref. [48]. It was shown that the morphology of Ti-Ta alloy critically depends on Ta concentration: a lamellar or needle-like martensitic structure can form depending on the amount of Ta. Thus, the thickness of the layer I grows during thermocycling due to the ongoing diffusion of Ti into Ta.

A mechanical mixture in the layer II of the sample produced using mode 1 is similar to those formed when using Ti-22.5Cr-7.5V-3Be filler metal [49]. More likely that the bright-contrast phases in the layers III and IV were formed due to decreasing of Ta solubility in Ti solid-solution [50]. The formation of the layer IV is related to crystallization of the residual brazing alloy melt, because the composition is similar to the initial one, especially for Ti. Hence $30 \mathrm{~min}$ are not enough to complete dissolution of the braze, and 
therefore we can expect achieving better results using longer brazing time.

Evidently, the phase II in the mode 2 sample (Fig. 7d) is the Laves $\mathrm{TaCr}_{2}$ phase [51, 52]. Likely, the formation of this phase occurred due to release of $\mathrm{Cr}$ from the SA. Layer III is a result of crystallization after dissolution in a brazing alloy melt. Probably, the initial boundary of the SA was between the layers III and IV, because Y was not found in the layers I-III.

The microstructure of RUSFER in the mode 2 specimen was investigated, which corresponds to those that should be formed after traditional heat treatment [53]. It is important to mention that compared with the joints obtained with $\mathrm{V}$ interlayer, no significant formation of Ferritic grains close to the seam were observed, because neither vanadium nor titanium carbides were formed. Ferritic grains are 10 times smaller than those observed in Ref. [54] under similar conditions and in Ref. [55] after brazing at $960{ }^{\circ} \mathrm{C}$. Also, the grain size is 20 times smaller than in Ref. [56] after HIP at $1050{ }^{\circ} \mathrm{C}$.

The investigation of the brazed joints of the SA and RUSFER steel allows us to make a conclusion on relevance of the brazing technology for a mock-up production. However, simultaneous brazing and heat treatment with the RAFM steel with temperature higher than $1000{ }^{\circ} \mathrm{C}$ is impossible due to the decay of the $\mathrm{W}-\mathrm{Cr}$ solid solution. Brazing at temperatures lower than $1000{ }^{\circ} \mathrm{C}$, even at $950{ }^{\circ} \mathrm{C}$, preserves the microstructure of the SA. A brazed joint with Ta interlayer can withstand at least 100 cycles of $300-600{ }^{\circ} \mathrm{C}$ heating and cooling down and expectedly even more, because no macro degradation was observed.

\section{Conclusion}

In the course of the paper, we have reviewed the first steps made towards realizing a first wall component for a future fusion power plant. This activity was pursued via the study of joining the smart $\mathrm{W}-\mathrm{Cr}-\mathrm{Y}$ tungsten alloy foreseen for a first wall of a fusion power plant and the reduced-activation RUSFER steel. Fully reduced activated $48 \mathrm{Ti}-48 \mathrm{Zr}-4 \mathrm{Be}$ wt.\% brazing alloy was first time used to join tungsten alloy with steel. Brazing of the SA should be carried out at a temperature not higher than $950{ }^{\circ} \mathrm{C}$ to prevent the decay of the W-Cr solid solution. RUSFER/Ta/SA brazed joint obtained by $48 \mathrm{Ti}-48 \mathrm{Zr}-4 \mathrm{Be}$ wt. $\%$ at $950{ }^{\circ} \mathrm{C} / 30 \mathrm{~min}$ brazing mode was capable to maintain the stable joint which retained its full mechanical integrity after the thermocycling for at least 100 cycles in the temperature range $300-600{ }^{\circ} \mathrm{C}$. This means that further investigations, such as mechanical tests and high heat flux tests, can be carried out.

At the same time, next steps for an industrial up-scaling were undertaken successfully. The bulk smart alloy sample with the size of $50 \mathrm{~mm}$ was realized successfully via field-assisted sintering technology. The $\emptyset 13$ and $\emptyset 20 \mathrm{~mm}$ SA samples feature a similar density and microstructure due to the similar sintering parameters of sintering temperature and current loading manner. Changing sample size and applied pressure during the up-scaling production SA sample, the factors of current density, heating rate, densification temperature and heat dissipation condition should be considered to achieve a desired density and a microstructure. In addition, the described study of FAST parameters has allowed an effective suppression of the chromium-rich phase formation in the course of sintering.

\section{Outlook}

Progress attained both in the area of brazing and industrial up-scaling allows us to pursue the activities in realization of the first wall prototype of the future fusion power plant. Both aforementioned activities are now about to be merged on the way of creation of the full-scale prototype of a first wall segment. The efforts will be focused in realizing the large full-scale joint of the smart alloy on the reduced-activation steel. This will be attempted along with brazing technology described here and by means of other innovative techniques. Among them, there is a direct sintering of smart alloy and steel via FAST and HIP. A pioneering research on direct sintering the materials and the joint in one-step using FAST and HIP is underway. The comparative study of all feasible joint techniques is foreseen.

Acknowledgements A part of these studies has been carried out within the framework of the EUROfusion Consortium and has received funding from the Euratom research and training programme 2014-2018 and 2019-2020 under grant agreement No. 633053. The views and opinions expressed herein do not necessarily reflect those of the European Commission. The research benefitted from a grant of the European Commission through the Erasmus Mundus International Doctoral College in Fusion Science and Engineering (FUSION-DC). Up-scaling production part is supported by the National Natural Science Foundation of China (Grant Nos. 52020105014 and 52001104), the Fundamental Research Funds for the Central Universities (Grant Nos. JZ2019HGTA0040, JZ2019HGBZ0113, and PA2019GDZC0096), the Natural Science Foundation of Anhui Province (Grant Nos. 201904b11020034 and 1908085ME115) and the International Postdoctoral Exchange Fellowship Program of Helmholtz-OCPC (Grant No. ZD20191015). Brazing part was funded by The Council for Grants of the President of the Russian Federation

Funding Open Access funding enabled and organized by Projekt DEAL.

Open Access This article is licensed under a Creative Commons Attribution 4.0 International License, which permits use, sharing, adaptation, distribution and reproduction in any medium or format, as long as you give appropriate credit to the original author(s) and the source, provide a link to the Creative Commons licence, and indicate if changes were made. The images or other third party material in this article are 
included in the article's Creative Commons licence, unless indicated otherwise in a credit line to the material. If material is not included in the article's Creative Commons licence and your intended use is not permitted by statutory regulation or exceeds the permitted use, you will need to obtain permission directly from the copyright holder. To view a copy of this licence, visit http://creativecommons.org/licenses/by/4.0/.

\section{References}

1. Zohm H, Angioni C, Fable E, Federici G, Gantenbein G, Hartmann T, Lackner K, Poli E, Porte L, Sauter O, Tardini G, Ward D, Wischmeier M. On the physics guidelines for a tokamak DEMO. Nucl Fusion. 2013;53(7):073019.

2. Federici G, Biel W, Gilbert MR, Kemp R, Taylor N, Wenninger R. European DEMO design strategy and consequences for materials. Nucl Fusion. 2017;57(9):92002.

3. Maisonnier D, Cook I, Sardain P, Andreani R, Pace Di L, Forrest R, Giancarli L, Hermsmeyer S, Norajitra P, Taylor N, Ward D. A conceptual study of commercial fusion power plants. Final report of the European Fusion Power Plant Conceptual Study (PPCS). A Concept Study Commer Fusion Power Plants Final Rep Eur Fusion Power Plant Concept Study 2005;1(5):1.

4. Wegener T, Klein F, Litnovsky A, Rasinski M, Brinkmann J, Koch F, Linsmeier C. Development of yttrium-containing selfpassivating tungsten alloys for future fusion power plants. Nucl Mater Energy. 2016;9:394

5. Koch F, Bolt H. Self passivating W-based alloys as plasma facing material for nuclear fusion. Phys Scr. 2007;T128:100.

6. Litnovsky A, Wegener T, Klein F, Linsmeier C, Rasinski M, Kreter A, Unterberg B, Coenen JW, Du H, Mayer J, GarciaRosales C, Calvo A, Ordas N. Smart tungsten alloys as a material for the first wall of a future fusion power plant. Nucl Fusion. 2017;57(6):066020.

7. Litnovsky A, Wegener T, Klein F, Linsmeier C, Rasinski M, Kreter A, Tan X, Schmitz J, Mao Y, Coenen JW, Bram M, Gonzalez-Julian J. Advanced smart tungsten alloys for a future fusion power plant. Plasma Phys Control Fusion. 2017;59(6):064003.

8. Litnovsky A, Wegener T, Klein F, Linsmeier C, Rasinski M. New oxidation-resistant tungsten alloys for use in the nuclear fusion reactors. Phys Scr. 2017;T170:014012.

9. Schmitz J. Development of tungsten alloy plasma-facing materials for the fusion power plant. Gent: Ghent University and University of Bochum. 2020.

10. Klein F, Wegener T, Litnovsky A, Rasinski M, Tan XY, GonzalezJulian J, Schmitz J, Bram M, Coenen JW, Linsmeier C. Oxidation resistance of bulk plasma-facing tungsten alloys. Nucl Mater Energy. 2018;15:226

11. Elio F, Ioki K, Bruno L, Cardella A, Gohar Y, Hechler M, Kodama T, Lodato A, Loesser D, Lousteau D, Lousteau D, Miki N, Mohri K, Parker R, Raffray R, Williamson D, Yamada M, Daenner, Mattas R, Strebkov Y, Takatsu H. Progress in the ITER blanket design. 17th IEEE/NPSS Symposium Fusion Engineering (Cat. No.97CH36131), San Diego, CA, USA, vol. 2. 1997. p. 987.

12. Raffray AR, Merola M. Design of the ITER first wall and blanket. 2011 IEEE/NPSS 24th Symposium on Fusion Engineering, Chicago, IL, USA, 2011. p. 1.

13. Calvo A, García-Rosales C, Ordás N, Iturriza I, Schlueter K, Koch F, Pintsuk G, Tejado E, Pastor JY. Self-passivating WCr-Y alloys: characterization and testing. Fusion Eng Des. 2017; 124:1118.

14. Lee G, Olevsky EA, Manière $\mathrm{C}$, Maximenko A, Izhvanov O, Back $\mathrm{C}$, McKittrick J. Effect of electric current on densification behavior of conductive ceramic powders consolidated by spark plasma sintering. Acta Mater. 2018;144:524.
15. Narayan J. A new mechanism for field-assisted processing and flash sintering of materials. Scr Mater. 2013;69(2):107.

16. Wang WJ, Tan XY, Liu JQ, Chen X, Wu M, Luo LM, Zhu XY, Chen HY, Mao YR, Litnovsky A, Coenen JW, Linsmeier Ch, Wu $\mathrm{YC}$. The influence of heating rate on $\mathrm{W}-\mathrm{Cr}-\mathrm{Zr}$ alloy densification process and microstructure evolution during spark plasma sintering. Powder Technol. 2020;370:9.

17. Wu Y. Manufacturing of tungsten and tungsten composites for fusion application via different routes. Tungsten. 2019;1(1):80.

18. Frisk K, Gustafson P. An assessment of the Cr-Mo-W system. Calphad. 1988;12(3):247.

19. Li X, Zhang L, Dong Y, Gao R, Qin M, Qu X, Li J. Pressureless two-step sintering of ultrafine-grained tungsten. Acta Mater. 2020;186:116

20. Lublinsky IE, Sevryukov ON, Vertkov AV, Ivannikov AA, Penyaz MA, Fedotov I, Peklich AS, Abramov ER. Experimental and numerical analysis of filler metal Stemet 1301A for connection of molybdenum with Steel 12CR18NI10TI. J Mater Process Technol. 2020. https://doi.org/10.1016/j.jmatprotec.2020.116683.

21. Logvenchev IS, Ivannikov AA, Volkov AA, Arofikin NV, Sevryukov ON, Fedotov VT, Suchkov AN, Fedotov IV, Skrytnyi VI. The brazing of nickel alloys for nuclear reactor with the using of the rapidly-quenched filler metals. Inorg Mater Appl Res. 2014;5(3):263.

22. Elrefaey A. High-temperature brazing in aerospace engineering. In: Chaturvedi MC, editor. Welding and joining of aerospace materials. Cambridge: Woodhead Publishing Ltd.; 2011. p. 345.

23. Fedorov $\mathrm{V}$, Uhlig $\mathrm{T}$, Wagner $\mathrm{G}$. Investigation of fatigue damage in aluminum/stainless steel brazed joints. Weld World. 2018;62:609.

24. Tillmann W, Walther F, Manka M, Schmiedt A, Wojarski L, Eilers A, Reker DW. Investigations of the corrosion damage process of the brazed joint AISI 304L/BNi-2. Results Phys. 2019;12:1245.

25. Riccardi B, Gavila P, Andrade J, Escourbiac F, Fedosov A, Durocher A, Kuznetcov V. Progress of the EU activities for the ITER divertor inner vertical target procurement. Fusion Eng Des. 2019; $146: 1524$.

26. Gervash A, Giniyatulin R, Guryeva T, Glazunov D, Kuznetsov V, Mazul I, Ogursky, Piskarev P, Safronov V, Eaton R, Raffray $\mathrm{R}$, Sevryukov O. The development of technology of $\mathrm{Be} / \mathrm{CuCrZr}$ joining using induction brazing. Fusion Eng Des. 2019;146:2292.

27. Litunovsky N, Alekseenko E, Makhankov A, Mazul I. Development of the armoring technique for ITER Divertor Dome. Fusion Eng Des. 2011;86(9-11):1749.

28. Cai Q, Liu W, Ma Y, Wang Z. Diffusion brazing of tungsten and steel using Ti-Ni liquid phase forming interlayer. Fusion Eng Des. 2015;91:67.

29. de Prado J, Sánchez M, Ureña A. Evaluation of mechanically alloyed $\mathrm{Cu}$-based powders as filler alloy for brazing tungsten to a reduced activation ferritic-martensitic steel. J Nucl Mater. 2017;490:188.

30. Tanner LE, Ray R, Cline CF. Amorphous metal alloys in the beryllium-titanium-zirconium system. US Patent: US 4050931, 1977.

31. Fedotov IV, Suchkov AN, Fedotov VT, Sevryukov ON, Kalin BA, Ivannikov AA. Brazing of hexagonal boron-nitride ceramics with VT1-0 titanium alloy using a rapidly quenched titanium-based brazing alloy. Weld Int. 2015;29(3):222

32. Gilbert MR, Sublet J-C, Forrest RA. Handbook of activation, transmutation, and radiation damage properties of the elements simulated using FISPACT-II and TENDL-2014; Magnetic Fusion Plants. Ccfe-R(15)26 2015;1.

33. Ioltukhovsky AG, Leontyeva-Smirnova MV, Kazennov YI, Medvedeva EA, Tselishchev AV, Shamardin VK, Povstyanko AV, Ostrovsky SE, Dvoryashin AM, Porollo SI, Vorobyev AN, Khabarov VS. Influence of operation conditions on structure and 
properties of $12 \% \mathrm{Cr}$ steels as candidate structural materials for fusion reactor. J Nucl Mater. 1998;258-263(Part 2):1312.

34. Basuki WW, Aktaa J. Investigation on the diffusion bonding of tungsten and EUROFER97. J Nucl Mater. 2011;417(1-3):524.

35. Bachurina D, Suchkov A, Kalin B, Sevriukov O, Fedotov I, Dzhumaev P, Ivannikov A, Leonteva-Smirnova M, Mozhanov E. Joining of tungsten with low-activation ferritic-martensitic steel and vanadium alloys for demo reactor. Nucl Mater Energy. 2018;15:135.

36. Villars P, Okamoto H. Ta-Zr Binary Phase Diagram 0-100 at.\% Zr. https://materials.springer.com/isp/phase-diagram/docs/c_ 0101221. Accessed 1 Dec 2020.

37. Villars P, Okamoto H. V-Zr Binary Phase Diagram 0-100 at.\% Zr. https://materials.springer.com/isp/phase-diagram/docs/c_ 0905433,. Accessed 1 Dec 2020.

38. Litovchenko IY, Polekhina NA, Tyumentsev AN, Astafurova EG, Chernov VM, Leontyeva-Smirnova MV. The effect of heat treatment on the microstructure and mechanical properties of heat-resistant ferritic-martensitic steel EK-181. J Nucl Mater. 2014;455(1):665.

39. Heuer S, Coenen JW, Pintsuk G, Matějícek J, Vilémová M, Linsmeier C. Overview of challenges and developments in joining tungsten and steel for future fusion reactors. Phys Scr. 2020;T171:14028.

40. Chernov VM, Leonteva-Smirnova MV, Mozhanov EM, Nikolaeva NS, Tyumentsev AN, Polekhina NA, Litovchenko IY, Astafurova EG. Thermal stability of the microstructure of $12 \%$ chromium ferritic-martensitic steels after long-term aging at high temperatures. Tech Phys. 2016;61(2):209.

41. Van der Schaaf B, Tavassoli F, Fazio C, Rigal E, Diegele E, Lindau R, LeMarois G. The development of EUROFER reduced activation steel. Fusion Eng Des. 2003;69(1-4):197.

42. Stork D, Agostini P, Boutard JL, Buckthorpe D, Diegele E, Dudarev SL, English C, Federici G, Gilbert MR, Gonzalez S, Ibarra A, Linsmeier Ch, Puma AL, Marbach G, Packer LW, Raj B, Rieth M, Quang-Tran M, Ward DJ, Zinkle SJ. Materials R\&D for a timely DEMO: key findings and recommendations of the EU Roadmap Materials Assessment Group. Fusion Eng Des. 2014;86:1586.

43. Huang Y, Cismondi F, Diegele E, Federici G, Del A, Moro F, Ghoniem N. Thermo-structural design of the European DEMO water-cooled blanket with a multiscale-multiphysics framework. Fusion Eng Des. 2018;135:31.

44. Harrington C. Dynamic modelling of balance of plant systems for a pulsed DEMO power plant. Fusion Eng Des. 2015;98-99:2147.

45. Calvo A, García-Rosales C, Koch F, Ordás N, Iturriza I, Greuner H, Pintsuk G, Sarbu C. Manufacturing and testing of self-passivating tungsten alloys of different composition. Nucl Mater Energy. 2016;9:422.

46. Villars P, Okamoto H. Cr-W Binary Phase Diagram 0-100 at.\%. https://materials.springer.com/isp/phase-diagram/docs/c_09042 01. Accessed 1 Dec 2020.

47. de Prado J, Sánchez M, Calvo A, García-Rosales C, Ureña A. Development of self passivating W-Eurofer brazed joints. Fusion Eng Des. 2019;146:1810.

48. Zhou YL, Niinomi M, Akahori T. Effects of Ta content on Young's modulus and tensile properties of binary Ti-Ta alloys for biomedical applications. Mater Sci Eng A. 2004;371(1-2):283

49. Kalin BA, Fedotov VT, Sevrjukov ON, Kalashnikov AN, Suchkov AN, Moeslang A, Rohde M. Development of brazing foils to join monocrystalline tungsten alloys with ODS-EUROFER steel. J Nucl Mater. 2007;367-370(Part B): 1218.

50. Villars P, Okamoto H. Ta-Ti Binary Phase Diagram 0-100 at.\% Ti. https://materials.springer.com/isp/phase-diagram/docs/c_ 0103641. Accessed 1 Dec 2020.

51. Villars P, Cenzual K. TaCr2 Crystal Structure. https://materials. springer.com/isp/crystallographic/docs/sd_0260899. Accessed 1 Dec 2020.
52. Villars P, Okamoto H. Cr-Ta Binary Phase Diagram 0-100 at.\% Ta. https://materials.springer.com/isp/phase-diagram/docs/c_ 0907169. Accessed 1 Dec 2020.

53. Ioltukhovskii AG, Leont'eva-Smirnova MV, Chernov VM, Tsvelev VV, Solonin MI, Golovanov VN, Shamardin VK. Development of new-generation high-temperature $12 \%$ chromium steel $16 \mathrm{Kh} 12 \mathrm{~V} 2 \mathrm{FTaR}$ with rapid decline of the induced activity for the atomic power engineering of Russia. Metal Science \& Heat Treatment. 2002;44:482.

54. Bachurina D, Suchkov A, Filimonov A, Fedotov I, Savelyev M, Sevryukov O, Kalin B. High-temperature brazing of tungsten with steel by Cu-based ribbon brazing alloys for DEMO. Fusion Eng Des. 2019;146:1343.

55. de Prado J, Sánchez M, Ureña A. Wettability study of a Cu-Ti alloy on tungsten and EUROFER substrates for brazing components of DEMO fusion reactor. Mater Des. 2016;99:93.

56. Basuki WW, Aktaa J. Diffusion bonding between W and EUROFER97 using V interlayer. J Nucl Mater. 2012;429(1-3):335.

Publisher's Note Springer Nature remains neutral with regard to jurisdictional claims in published maps and institutional affiliations.

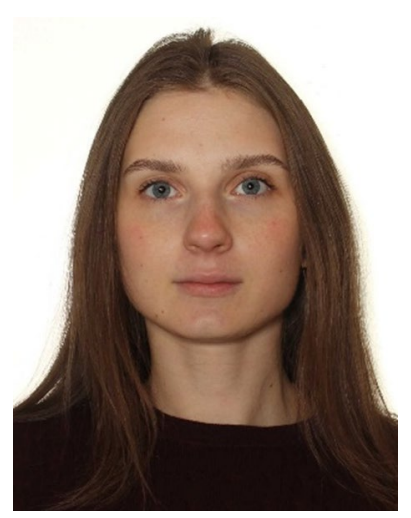

Ms. Diana Bachurina is a Ph.D. student at the Department of Materials Science, National Research Nuclear University MEPhI, Moscow, Russia. Diana has received two individual grants from the Russian Federation Government, including The Council for Grants of the President of the Russian Federation and Russian Foundation of Basic Research. Diana does research in Solid State Physics, Materials Science and Materials Physics. Her main subject is a development of a brazing process for dissimilar joints, including development of a filler alloy composition, brazing mode and their investigations. Her current project is "Joining tungsten to steel for DEMO application". Moreover, she has been working on the stress corrosion cracking of nuclear materials.

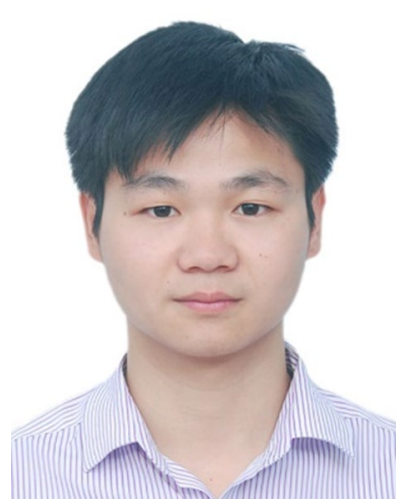

Dr. Xiao-Yue Tan got his Ph.D. degree from the school of materials science and engineering, Hefei University of Technology, China in 2018. After then, he works at Hefei University of Technology as a young lecturer. Since December 2019, he won a fund supported by the international postdoctoral exchange fellowship program of HelmholtzOCPC and has worked as a Sino-Germany postdoc at the Forschungszentrum Jülich, Germany for two years. His research interests include the design and preparation of anti-oxidant tungsten alloys, the microstructure influence on physical and mechanical properties of tungsten materials. Until now, he has published more than 50 research papers and been authorized nearly 10 patents. 